\title{
The 2016 SAMREC Code
}

\author{
by K. Lomberg* and S.M. Rupprecht ${ }^{\dagger}$
}

\section{Synopsis}

The SAMREC Code is a guideline that stipulates the minimum standards for the reporting of Exploration Results, Mineral Resources, and Mineral Reserves; adds credibility to declarations by project promoters, and assists in comparisons due to the uniform basis of the declaration, assists professionals by providing guidance; assists the Competent Person to demonstrate the legitimacy of the declaration, and provides credibility to Public Reporting.

The SAMREC Code provides guidelines and acts as one of the fundamental mechanisms to assist in the progression of mining projects. Importantly, it holds professionals accountable for their work, but does not specify the technical details relating to estimating Exploration Results, Mineral Resources, and Mineral Reserves. The SAMREC Code does provide guidance in the estimation and declaration of Exploration Results, Mineral Resources and Mineral Reserves; thus endorsing the sustainability of the mineral industry.

A revision of the SAMREC Code was necessary because the mineral industry has advanced and has changed focus as the prevailing economic and political circumstances have changed. The manner in which projects and mines are funded, developed, and operated is continually altering; there are shifting requirements by the investment community, government, and society (social license to operate); there is a need to promote greater efficiency in capital raising and funding for exploration, mining, and production companies; and the SAMREC Code must keep abreast of the advances made by other international reporting codes and eliminate possible contradictory reporting practices.

The aspects that have been addressed and updated in the 2016 SAMREC code are as follows:

> The complete adoption of the Combined Reserves International Reporting Standards Committee (CRIRSCO) standard definitions

> Additional assistance with the understanding and reporting of Exploration Results

> The inclusion of a new table format and the adoption of the 'If not, why not' principle in reporting

> Further emphasis on economics and transparency/materiality

> Additional Technical Studies definitions and the inclusion of guidelines in terms of the composition of Technical Studies

> Provision of clarity as to the point of reference for a declaration

> Making a site visit by the Competent Person mandatory

> Revision of aspects relating to coal and improved alignment with SANS 10320

> The provision of a more comprehensive diamond and gemstone section

> The introduction of a section on industrial minerals and metal equivalents

> Inclusion of recommendations for a table of contents, signature page, glossary of terms, and updating of definitions.

The objective of this paper is to inform the reader of the changes to the SAMREC Code and to re-emphasize best practice for the declaration of Exploration Results, Mineral Resources, and Mineral Reserves.

Keywords

Reporting codes, SAMREC 2016.

\section{Background}

The development of the Combined Reserves International Reporting Standards Committee (CRIRSCO) family of international reporting codes is a response to a number of mining industry 'bubbles', e.g. the Poseidon nickel boom and bust of 1969/70 and the Bre-X scandal of 1997. Although the USA and Australia had already started developing their codes (1988 and 1989 respectively), the international initiative to standardize reporting definitions for Mineral Resources and Mineral Reserves began at the 15th Council of Mining and Metallurgical Institutions (CMMI)

Congress at Sun City, South Africa in 1994.

The ad-hoc International Definitions Group (later to become CRIRSCO) was tasked with the primary objective of developing a set of international standard definitions for the reporting of Mineral Resources and Mineral Reserves. Deliberations continued, with agreement being reached for the definitions of the two major categories, Mineral Resources and Mineral Reserves, and their respective sub-categories Measured, Indicated, and Inferred Mineral Resource, and Proved and Probable Mineral Reserves under the Denver Accord in 1997. Following these agreements, an updated version of the JORC Code was released in Australia in 1999 and the first SAMREC Code was issued in 2000.

In 2002, the Combined Reserves International Reporting Standards Committee (CRIRSCO, now known as the Committee for Mineral Reserves International Reporting Standards) was formed, replacing the CMMI International Definitions Group with the mission to continue coordination between

* Coffey Mining (SA) Pty Ltd, South Africa.

+ University of Johannesburg, South Africa.

(c) The Southern African Institute of Mining and Metallurgy, 2017. ISSN 2225-6253. This paper was first presented at the SAMREC/SAMVAL Companion Volume Conference 'An Industry Standard for Mining Professionals in South Africa', 17-18 May 2016, Emperors Palace, Johannesburg 


\section{The 2016 SAMREC Code}

member countries for the development of international standards for the definition and reporting of Exploration Results, Mineral Resources, and Mineral Reserves. Subsequently, various other codes have been developed based on the CRIRSCO template. These now include nine national/regional reporting organizations (NROs): namely Australasia (JORC), Brazil (CBRR), Canada (CIM), Chile (National Committee), Europe (National Committee PERC), Mongolia (MPIGM), Russia (OERN), South Africa (SAMREC), and the USA (SME). The combined value of mining companies listed on the stock exchanges of these countries accounts for more than $80 \%$ of the listed capital of the mining industry (CRIRSCO website).

\section{The importance of the reporting codes}

The mining industry is a vital contributor to national, regional, and international economies. There is a continuous demand for various mineral and metal commodities that necessitates finding new deposits, as well as developing more efficient, safer, and cheaper ways of mining and processing minerals. In an ever-changing world, new products are continuously being developed that require new commodities or the continued production of existing commodities. Commodities are frequently discovered in one area, beneficiated and refined in another, and sold or used in yet another location. The mining industry therefore transcends international boundaries and 'depends on the trust and confidence of investors and other stakeholders for its operational well-being' (CRIRSCO website).

The process of developing a mining project or mine involves technical expertise, requires a substantial and longterm capital investment, and carries numerous uncertainties and risks. Unlike many other industries, mining is based on depleting assets, the knowledge of which is imperfect prior to the commencement of extraction. To mitigate the risks and obtain support (financial, political, social etc.) for the investment, a detailed technical, financial, environmental, governmental, and social understanding of the project/mine is required. It is therefore essential that the industry is able to communicate the investment risks effectively and thus provide a level of trust and confidence for investors and other stakeholders to allow project progression and a sustainable operation. Part of the communication is provided by the declaration of Mineral Resources and Mineral Reserves. The international codes provide significant guidelines that inter alia provide a common understanding of the project/mine.

'The international mining industry has a need to communicate effectively. With meaningful standards in place and enforced, sound decision can be made by various stakeholders in their participation in a project, as well as the best way to progress it' (Rendu, 2000).

The aim of the SAMREC Code is to contribute to gaining and maintaining the trust of potential investors and other interested parties and stakeholders by promoting high standards of reporting of mineral estimates (Mineral Resources and Mineral Reserves) and of exploration progress (Exploration Results). Furthermore, the SAMREC Code contains specific guidelines for the Public Reporting of Exploration Results, Mineral Resources, and Mineral Reserves for mineral projects and mines. The SAMREC Code:
> Provides minimum standards for reporting of Exploration Results, Mineral Resources, and Mineral Reserves

> Adds credibility to declarations by project promoters and assists in the comparison with similar projects due to the uniform basis of declaration

> Assists professionals by providing guidance

> Assists the Competent Person to demonstrate the legitimacy of the declaration and provides credibility to the Public Report.

\section{Role of the SAMREC Code}

The SAMREC Code does not specify the technical details relating to estimating Exploration Results, Mineral Resources, and Mineral Reserves. The interpretation of the raw data, the geological interpretation, engineering design, infrastructure requirements, and governmental, social, and environmental inputs are all required to be based on the contribution of specialists and signed off by a Competent Person. Because the geological model is open to interpretation and has a huge influence on the mine design and associated financial outlook of the mine or project, there is a need for guidelines. The SAMREC Code provides these guidelines and a mechanism to assist in the progression of mining projects, which includes holding professionals (Compentent Persons) accountable for their work.

Over and above the technical work, the SAMREC Code requires the Competent Person to justify and document the technical inputs and the process underlying the declaration of Exploration Results, Mineral Resources, and Mineral Reserves. This approach relies on the Competent Person being prepared to face his/her peers and willing to take responsibility for the result.

The aim of the SAMREC Code is to develop and maintain the trust of investors and other interested and affected parties by promoting high standards of Public Reporting. The SAMREC Code represents the minimum reporting standard and compels the Competent Person to rather report 'more information than the barest minimum'. The SAMREC Code provides the guiding principles that support these declarations.

\section{Changes to the SAMREC code}

As a result of increasing professionalism and updated methodologies, it is necessary to regularly review and update the SAMREC Code because:

> The minerals industry has advanced and changed focus as the prevailing economic and political circumstances have evolved

> The manner in which projects and mines are funded, developed, and operated is continually changing

> The requirements of the investment community, government, and society (social licence to operate) are shifting

> There is a need to promote greater efficiency in capital raising and utilization of funds for exploration, mining, and beneficiation

> The SAMREC Code must keep abreast of the advances made by other international reporting codes and eliminate possible contradictory reporting practices. 


\section{The 2016 SAMREC Code}

\section{CRIRSCO standard definitions adopted}

In recent years, CRIRSCO has worked towards aligning all the international reporting codes so that the definitions used in the extractive industries are globally consistent. This consistency is based on insisting that the 15 standard definitions are commonly applied to all the international Codes (CRIRSCO, 2013). The following are the standard definitions commonly applied by CRIRSCO members:

$\begin{array}{ll}\text { Public Reports } & \text { Measured Resource } \\ \text { Competent Person } & \text { Mineral Reserve } \\ \text { Modifying Factors } & \text { Probable Reserve } \\ \text { Exploration Target } & \text { Proved Reserve } \\ \text { Exploration Results } & \text { Scoping Study } \\ \text { Mineral Resource } & \text { Pre-Feasibility Study } \\ \text { Indicated Resource } & \text { Feasibility Study } \\ \text { Inferred Resource } & \end{array}$

Consequently, the definitions in the SAMREC Code are required to be either identical to, or not materially different from, the other international definitions.

\section{Exploration Results}

The reporting of Exploration Results has occasionally been misused (or abused) as some Competent Persons have tended to be selective in their reporting. Because reporting of Exploration Results represents the entry level to declarations, a lot of effort has been made to ensure that these declarations are considered balanced reporting. Clause 18 of the SAMREC Code has been updated with the intention that Exploration Results must not be 'presented in a way that unreasonably implies the discovery of potentially economic mineralisation' and should include relevant data and information relating to the mineral property (both positive and negative). The SAMREC Code further advises that 'historical data and information may also be included if, in the considered opinion of the Competent Person, such is relevant, giving reasons for such conclusions'. Guidance has also been provided that 'the data and information may be derived from adjacent or nearby properties if the Competent Person can provide justification of continuity for such an association' (Rupprecht, 2015). Also, the deposit is referred to as 'Mineralisation' so as not to imply any degree of technical or economic study.

The reporting of Exploration Targets in the updated 2016 SAMREC Code has not changed in that a range of tons and grade has to be reported. However, guidance is provided in the use of the data maxima and minima being required, and the requirement that an Exploration Target cannot be tabulated together with Mineral Resources and Mineral Reserves. It is hoped that this will clearly indicate the low level of confidence in the information and ensure that a reported Exploration Target cannot be misconstrued or misrepresented as a Mineral Resource or Mineral Reserve.

\section{New reporting format}

The 2016 SAMREC Code provides a comprehensive checklist for the Competent Person in the form of Table I. One of the criticisms of the previous SAMREC Code has been the formulation of this table. The revised Table I is now in a 'landscape' format with each section numbered with Arabic numerals. Each sub-section that existed in the 2009 Table I has been included in the various sections and numbered using Roman numerals (Figure 1). Additional information was sourced from the other international reporting codes and where appropriate, the sub-sections of the original Table I reworded. It is believed that the new referencing will be easier for, inter alia, the JSE Reader requirements, and will assist Competent Persons to ensure they have addressed all the necessary reporting aspects.

The structure attempts to follow the logical project progression from the scientific aspects relating to the geology in the first few sections to the engineering aspects in the later sections. The structure also cascades from Exploration Results to Mineral Resources and then to Mineral Reserves (proceeding left to right in the table).

\begin{tabular}{|c|c|c|c|c|c|}
\hline \multicolumn{6}{|c|}{ SAMREC TABLE 1} \\
\hline & & & Exploration Results & Mineral Resources & Mineral Reserves \\
\hline \multicolumn{6}{|c|}{ Section 4: Estimation and Reporting of Exploration Results and Mineral Resources } \\
\hline \multirow[t]{6}{*}{4.1} & \multirow[t]{6}{*}{$\begin{array}{l}\text { Geological } \\
\text { model and } \\
\text { interpretation }\end{array}$} & (i) & \multicolumn{3}{|c|}{$\begin{array}{l}\text { Describe the geological model, construction technique and assumptions that forms the basis for the Exploration Results or Mineral } \\
\text { Resource estimate. Discuss the sufficiency of data density to assure continuity of mineralisation and geology and provide an adequate } \\
\text { basis for the estimation and classification procedures applied. }\end{array}$} \\
\hline & & (ii) & \multicolumn{3}{|c|}{$\begin{array}{l}\text { Describe the nature, detail and reliability of geological information with which lithological, structural, mineralogical, alteration or other } \\
\text { geological, geotechnical and geo-metallurgical characteristics were recorded. }\end{array}$} \\
\hline & & (iii) & $\begin{array}{l}\text { Describe any obvious geological, mining, } \\
\text { metallurgical, environmental, social, } \\
\text { infrastructural, legal and economic factors } \\
\text { that could have a significant effect on the } \\
\text { prospects of any possible exploration target } \\
\text { or deposit. }\end{array}$ & & \\
\hline & & (iv) & & \multicolumn{2}{|c|}{$\begin{array}{l}\text { Discuss all known geological data that could materially influence the estimated quantity and } \\
\text { quality of the Mineral Resource. }\end{array}$} \\
\hline & & (v) & & \multicolumn{2}{|c|}{$\begin{array}{l}\text { Discuss whether consideration was given to alternative interpretations or models and their } \\
\text { possible effect (or potential risk) if any, on the Mineral Resource estimate. }\end{array}$} \\
\hline & & (vi) & & \multicolumn{2}{|c|}{$\begin{array}{l}\text { Discuss geological discounts (e.g. magnitude, per reef, domain, etc.), applied in the model, } \\
\text { whether applied to mineralized and / or un-mineralized material (e.g. potholes, faults, } \\
\text { dykes, etc.). }\end{array}$} \\
\hline
\end{tabular}




\section{'If not, why not' reporting principle}

Table 1 in the 2016 SAMREC Code provides a comprehensive checklist of the various technical aspects that are required for an Exploration Results, Mineral Resources, or Mineral Reserve declaration. The use of the checklist for every declaration is considered best practice and if completed properly it can provide the Competent Person with assurance that no technical inputs or practices have been omitted. It also provides users with confidence that the declaration is fully compliant and can be relied upon. The revised SAMREC Code has included a requirement to report against Table 1 on an 'if not, why not' basis for maiden declarations and when a material change in the declaration has occurred for a significant project/mine. The reader is referred to the SAMREC Code glossary of terms for the definition of 'material' and a 'significant project'. The 2016 SAMREC Code requires that every aspect of the Table 1 (checklist) must be answered by the Competent Person so as to adequately address all key elements of the reporting of Exploration Results, Mineral Resources, and Mineral Reserves. Where aspects of this table are not included in the Public Report, the Competent Person is required to comment as to why they have not been addressed.

The motivation for this requirement is to improve 'transparency' and 'materiality', as well as making it more difficult to be 'opaque' or present 'selective' reporting in market releases or other Public Reports. 'If not, why not' reporting increases confidence in Public Reporting, as well as assisting the Competent Person to include all aspects that a reasonable stakeholder, investor, and advisors would expect to find in a Public Report. Furthermore, the reporting mechanism assists the Competent Person to provide all relevant details, whether they are perceived as positive or negative, in the Public Report.

\section{Emphasis on Economics and Transparency/ Materiality}

An 'if not, why not' approach is required in recognition of a perceived lack of transparency and/or materiality in Public Reporting. The SAMREC Committee felt that it was important that the aspects of balanced reporting are emphasized. An aspect often lacking in Public Reporting is the demonstration of 'reasonable prospects for eventual economic extraction'. To this end, various points have been added to Table 1 to provide more detail to stakeholders, investors, and advisers, and which are aimed at improving the communication of results and engendering trust and confidence in the industry.

\section{Technical studies}

The previous code contained definitions for Pre-Feasibility Study and Feasibility Study. This is appropriate, as the minimum requirement for the declaration of a Mineral Reserve is a Pre-Feasibility level study. The detailed requirements, although broadly understood, are frequently selectively considered. To assist in providing a common understanding, Table 2 has been included in the 2016 SAMREC Code to provide some detail and reduce the ambiguity of the definitions. It must be noted that these are generally recognized definitions and not mandatory.

Since the previous edition of the SAMREC Code the concept of Preliminary Economic Assessment (PEA) has become increasingly popular in Canada. This is a synonym for a Scoping Study. As a result, and following the CRIRSCO lead, the definition of 'Scoping Study' is provided and supported by information provided in Table 2 . It must be emphasized that a Scoping Study is not sufficient grounds to allow for the declaration of a Mineral Reserve.

\section{Independence}

Independence of the Competent Person has been a topic of debate within the mineral industry. The SAMREC Code allows employees and people who have a vested interest in a project to sign off as the Competent Person. However, the relationship with the commissioning entity must be clearly stated. Defining independence can at times be extremely difficult and complex and it is therefore left to the commissioning entity to define if independence is a requirement.

\section{Point of reference}

The declaration of a Mineral Resource and Mineral Reserve is linked to various common practices and economic realities. A declaration for precious and base metals typically reports grade as a head grade, i.e. prior to processing. However, the economics of bulk commodities and industrial minerals are linked to the saleable specification. Therefore, the concept of defining the point of reference has been introduced in the 2016 SAMREC Code to improve transparency and enhance communication and understanding.

\section{Site visit}

Until now, the necessity of a site visit has not been definitive. The SAMREC Code now requires a site visit to be undertaken by a Competent Person. This is without a doubt best practice and assists the Competent Person in fully appreciating the technical complexities of the assignment. However, where a site visit is impractical or impossible due to, for instance, political unrest, this should be declared. In this case, the Competent Person cannot abstain from taking responsibility, although a caveat may be appropriate.

\section{Revision of aspects relating to coal}

In parallel with the SAMREC Code update there has been a revision of the SANS coal standard (SANS 10320: South African Guide to the Systematic Evaluation of Coal Resources and Coal Reserves). It must be noted that this is a standard under the South African Bureau of Standards (SABS) and covers a slightly different ambit, which includes national reporting of Coal Resources and Coal Reserves. Nonetheless it includes various valuable aspects that are relevant to the declaration of Coal Resources and Coal Reserves. The SAMREC Code therefore requires that SANS 10320 is considered when preparing reports for Coal Resources or Coal Reserves. This has allowed the coal section of the 2016 SAMREC Code to be revised and abbreviated.

It must be noted that some aspects of coal reporting were previously not fully consistent with the SAMREC Code; for example, the requirement for a Feasibility Study to be completed in order to declare a Proved Coal Reserve. The classification of Proved and Probable Coal Reserves has been modified to reflect a minimum requirement of a PreFeasibility Study or Life of Mine Plan, which now aligns this definition with international requirements. An additional change to coal reporting is the removal of reporting of In-Situ Coal Reserves in the 2016 SAMREC Code. It should be noted that this later concept is not lost and is still part of the SANS standard - but is no longer included in the SAMREC Code. 


\section{More comprehensive diamond and gemstone section}

The 2009 SAMREC Code had a diamond section. However, the section was not considered adequate in terms of the requirements of Public Reporting, and a significant revision was undertaken to include a set of guidelines for consideration when a Competent Person makes a public declaration.

Ten additional clauses, as well as a diagram to demonstrate the relationship between Diamond Exploration Results, Diamond Resources, and Diamond Reserves, have been included in the 2016 SAMREC Code. Due to the number of changes in the diamond section of the Code and the specific nature of diamond reporting, readers are referred to the 2016 SAMREC Code for elaboration of these changes. Key areas discussed are:

$>$ Stone size distribution

$>$ Diamond price

- Geological domains

> Minimum representative parcel or samples for various deposits

> Use of kimberlitic indicator mineral chemistry in grade and value estimation

- Valuation of microdiamonds and sampling protocols

> Relationship between the micro- and macro-diamond portions of the size frequency distribution curve

$>$ Recovery factors.

\section{Introduction of a section on industrial minerals}

The reporting of industrial minerals is a new section in the SAMREC Code. The broadening of the ambit of Exploration Results, Mineral Resources, and Mineral Reserves has necessitated that more specific information be provided when dealing with industrial minerals. Aspects mentioned include the importance of a market and the saleable specifications.

\section{Introduction of metal equivalents}

Metal equivalents are a contentious issue. However, some guidance is required and specifically the minimum requirements of grades, recoveries, and metal prices are emphasized. These have been included as a separate section in the SAMREC Code to provide better understanding and communication to the various stakeholders and interested and affected persons or parties.

\section{Table of contents}

Canadian National Instrument (NI) 43-101 is often considered a superior form of reporting due to its structure. The structure, like the guidelines in the SAMREC Code, does not guarantee the quality of the Public Report, which remains the responsibility of the Competent Person. However, the 2016 SAMREC Code now includes a suggested table of contents to assist the Competent Person in providing a readable document and improve communication of the technical aspects.

\section{Glossary of terms and updating of definitions}

Key changes to the SAMREC Code include the updating of the glossary of terms to provide a minimal consistency with the CRIRSCO Reporting Template. For instance, the definition of a Recognised Overseas Professional Organisation (ROPO) was updated to Recognised Professional Organisation (RPO). Other terms, such items as review, Competent Person's Report, and audit have been added to the glossary of terms.

\section{Signature page}

The Competent Person must take responsibility for his/her work. The guidance provided in the form of a suggested signature page is aimed at identifying the Competent Person, noting their qualifications, affiliations, and relevant experience, as well as demonstrating that the Competent Person has indeed taken responsibility for their work or their contribution to the Public Report.

\section{Revision of the classification diagram}

The classification diagram has been revised and although the change is minimal, the diagram (Figure 1 of the 2016 SAMREC Code) is now virtually the same as the CRIRSCO diagram. The important inclusion is Infrastructure as a Modifying Factor. In addition, specific diagrams have been drafted for coal and diamond classifications.

\section{PLATO replaced}

During the last few years the legislation affecting surveying has been revised in the form of the Geomatics Profession Act 19 of 2013. A consequence of this has been the disbanding of PLATO and the establishment of the South African Geomatics Council (SAGC) (statutory body) and the Institute of Mine Surveyors of South Africa (IMSSA) (learned society) to replace PLATO. These bodies have the necessary disciplinary codes and codes of ethics.

\section{Role of the Competent Person}

The designated Competent Person must be sure that they understand fully the meaning of the Competent Person designation and the responsibilities that go with it. Being a Competent Person is not only about the professional training a person has received, nor simply a matter of being in a supervisory role and certainly not just a matter of being designated - it means the person takes responsibility for their part of the Public Report. The responsibility of deeming oneself as a Competent Person lies with the individual as the 'Competent Person must be clearly satisfied in their own mind that they are able to face their peers and demonstrate competence in the commodity, type of deposit and situation under consideration' (SAMREC Code Clause 10). It is the responsibility of the Competent Person to be fully aware of all applicable rules and regulations before a signing off on a Public Report.

The key professions in Public Reporting and declarations in terms of the Code are geology, surveying, and mining engineering. They are, naturally, supported by a number of other professionals such as economists, metallurgists, engineers (geotechnical, ventilation, civil, mechanical, electrical etc.), environmentalists, social scientists/ practitioners, and lawyers.

\section{Geologist}

Geologists bring a range of important skills to the estimation of Mineral Resources, notably the discipline and rigor of science. Their interpretation of the often sparse data results in geological understanding and interpretation in the form of geological models. An important aspect of science is the ability to predict beyond the data. Geologists are able to assist in presenting the scientific aspects of a project/mine that allow the engineers to provide a technical solution for the exploitation of the mineralisation. The tool used is the geological model and associated grade or block model. The 


\section{The 2016 SAMREC Code}

value of the block model is that it provides the information necessary for mine and infrastructure design, supports the development of the mining schedule and informs mineral processing strategies, and underpins the declaration of Mineral Resources and Mineral Reserves.

\section{Surveyor}

The mine surveyor is one of the key contributors to the mining industry. Surveyors are responsible for maintaining accurate plans of the mine. More importantly, the surveyor is responsible for the measuring process that keeps account of the monthly production (tonnage and grade) of the operation. In addition to this, the volumes of the waste dumps and other surface stockpiles are frequently determined.

Mine surveying is considered to be a branch of mining science and technology and includes all measurements, calculations, and mapping that serve the purpose of ascertaining and documenting information at all stages from prospecting to exploitation and utilizing of mineral deposits by both surface and underground workings (International Society for Mine Surveying). Mine surveyors therefore work hand-in-hand with geologists and mining engineers, especially as regards the geometry of the deposit/orebody and the associated quality/grade. Mine surveyors assist with, and are an integral part of, the estimation of Mineral Resources and Mineral Reserves.

\section{Mining engineer}

The role of the mining engineer is to design, develop, and operate safe and efficient mines, whether surface or underground operations. Their role is to combine an understanding of the deposit with the various engineering disciplines by applying their technical knowledge and management skills. The mining engineer will assess the technical, engineering, and commercial viability of a project or mine. This requires the design of a possible mine, including geotechnical engineering, production requirements/profiles, equipment specifications, ventilation, health and safety, etc. These technical aspects may be reported in a Scoping Study, Pre-Feasibility Study or Feasibility Study, or Life of Mine Plan for an existing mine and will form the basis of the declaration of a Mineral Reserve. Mining engineers are able to undertake the various technical or engineering aspects of a mining operation, which are a series of very complex tasks, and formulate a mine plan and schedule that can be executed.

The financial valuation of a project or mine relies on geological and grade models that are the result of scientific modelling, together with engineering skills provided by the mining engineer and other experts and specialists.

\section{The way forward and the future}

The way forward for Competent Persons is to embrace the 2016 SAMREC Code and appropriately apply the guidelines. It is safe to assume that increased attention will be given to Public Reporting in the future, partly in response to the launch of the revised SAMREC Code. Use of the SAMREC Code should be motivated by the desire to provide the best technical output possible rather than by a fear of the consequence of making a mistake or being found on the wrong side of the SAMREC Code's guidelines. By complying with the SAMREC Code, Competent Persons can enhance their reputation and the reputation of the mining industry.
Although the revised SAMREC Code came into effect on 1 January 2017, there remain some unresolved issues, for example, the reporting of Mineral Resources inclusively or exclusively of Mineral Reserves, and the registration of Competent Persons. These are complex issues that will require further discussion. Other issues can be expected to arise in the future and will also need to be discussed. It is hoped that the solution to these issues and new issues can be resolved through public debate or articles on best practice rather than having to revise or update the Code in the near future.

\section{Conclusion}

In preparing a Public Report the practitioner must satisfy the requirements of the SAMREC Code. The intention of the SAMREC Code is to aid the Competent Person in the declaration of Exploration Results, Mineral Resources, and Mineral Reserves.

The authors acknowledge that no single document could cover all accepted industry practices or assist with all possible situations. However, the aim of the SAMREC Code is to provide guidance that represent the best current knowledge in terms of reporting practices. Competency and diligence are still required when applying the SAMREC Code, as the Competent Person must balance the unique situation of a deposit with best practices. Despite having the SAMREC Code available, Competent Persons are still required to be prepared to defend themselves to their peers and take responsibly for their work.

The amount of effort that may be required in complying with the revised Code must not be underestimated. However, the hope is that the industry will see improved communication and the positive progression of projects and mines as a result of these changes.

\section{Acknowledgments}

This paper could not have been written without the contributions made by the many friends and fellow professionals who have contributed to the writing and revision of the SAMREC Code over the last 15 years. Although the authors have been involved only in the last six years, we owe them an immense debt. Naming them all would be impossible.

\section{References}

BIRCH, C. 2014. New systems for geological modelling - black box or best practice? Journal of the Southern African Institute of Mining and Metallurgy, vol. 114. pp. 993-1000.

Blumer, J.M. 2000. The Valmin Code - Bible, Roadmap or Signpost? International Aspects of Resource and Reserve Reporting in MICA. The Codes Forum, Sydney.

RENDU, J.M. 2000. International aspects of Resource and Reserve Standards. International Aspects of Resource and Reserve Reporting in MICA. The Codes Forum, Sydney.

RuPPRECHT, S.M. 2015. The SAMREC Code 2105 - some thoughts and concerns. Journal of the Southern African Institute of Mining and Metallurgy, vol. 115, no. 11. pp. 987-991.

SAMREC. 2009. South African Mineral Resource Committee. The South African Code for Reporting of Exploration Results, Mineral Resources and Mineral Reserves (the SAMREC Code). 2007 Edition as amended July 2009. http://www.samcode.co.za/downloads/SAMREC2009.pdf

SAMREC. 2016. South African Mineral Resource Committee. The South African Code for the Reporting of Exploration Results, Mineral Resources and Mineral Reserves (the SAMREC Code). 2016 Edition. http://www.samcode.co.za/codes/category/8-reporting codes?download=120:samrec 